\title{
The value of car ownership and use in the United States
}

\author{
Joanna Moody', Elizabeth Farr $\oplus^{2}{ }^{2}$, Marisa Papagelis ${ }^{3}$ and David R. Keith $\oplus^{4} \llbracket$
} It is widely accepted that consumers underestimate the full cost of car ownership and that correcting this bias could meaning-
fully accelerate the adoption of shared mobility. Yet this argument fails to consider how much benefit consumers enjoy from
owning their own vehicle. Here we estimate the value of private car ownership and use in four US metro areas-Chicago, Illinois;
Dallas, Texas; Seattle, Washington; and Washington DC-using online discrete choice experiments. We find that, on average,
people would need to be paid $\$ 11,197$ to give up access to their privately owned vehicle for one year, which is at least as much as
estimates of the average total private cost of vehicle ownership $(-\$ 9,000)$. Critically, we find that more than half of this value
is non-use value-such as the option to travel whenever or wherever needed at a moment's notice and the status that comes
from owning one's own vehicle-beyond the use value of getting from A to B. Further, this non-use value was found to be much
higher during the COVID-19 pandemic. Our findings reframe the conversation around the transition away from private vehicle
dependence, emphasizing the need to provide value and convenience if alternative mobility solutions are to be widely adopted.

$P=$ eople in the United States depend on cars-91\% of adults commute to work using personal vehicles ${ }^{1}$, and cars provide a level of convenience that is often unmatched by other transportation modes. At the same time, car ownership is expensive ${ }^{2}$, and cars sit idle over $90 \%$ of the time, taking up vast amounts of space in our cities ${ }^{3-5}$. Why then do the majority of people in the United States and other countries still choose to own their own car? Why have we not been more attracted to on-demand mobility services, which allow us to avoid the upfront cost of purchasing a vehicle, let us pay only for what we use and require many fewer vehicles (and parking spaces) in our cities?

The dominant explanation for the abundance of private car ownership is that consumers systematically underestimate the true private cost of car ownership and that more people would forgo car ownership if this bias in their mental accounting were corrected ${ }^{6-11}$. Andor et $\mathrm{al} .{ }^{6}$ found that people underestimate the total cost of car ownership by $52 \%$ and concluded that if consumers did accurately account for the cost, they would own fewer cars.

Another possibility, however, is that the perceived value of car ownership and use exceeds the private costs and that owning one's own car is therefore rational for the majority of consumers. For many US households, access to a car unlocks economic opportunities such as jobs and education and time with family and friends ${ }^{12-14}$. In addition to the value that comes from the mobility it provides, researchers have found that consumers frequently attribute social status and pride to car ownership and use ${ }^{15-17}$. Even when a car is sitting idle, owning it provides the option value of driving at any time $^{18}$. If the value of car ownership and use exceeds the cost, consumers may continue to want privately owned cars even if lower-cost on-demand mobility solutions are available.

In this paper, we estimate the value of private car ownership and use in four US metro areas-Chicago, Illinois; Dallas, Texas; Seattle, Washington; and Washington DC-using two stated choice experiments that were conducted during the COVID-19 pandemic. Asking respondents to first think back to pre-pandemic times, we estimate a median value of car ownership and use of $\$ 11,197$ and find that the majority of this value $(\$ 6,497$, or $58 \%)$ can be attributed to ownership rather than use. We show further that respondents' perceptions of the non-use value of car ownership were much greater during the pandemic than before (the persistence of which will remain an open question into the future), highlighting how perceptions of value are conditioned by contextual factors. Across individuals, we find that those who travel more by car and less by other modes are less willing to give up their car and that the value of private car ownership and use is lower in urban areas compared with suburban and rural areas. Finally, the value of car ownership and use is estimated to be orders of magnitude higher than the value of other urban transportation options, including other car-based modes such as ride-hailing.

We quantify the average perceived value of owning and using a car in the United States using online choice experiments, providing important evidence that people value their cars more than their cost, and much more than other transportation alternatives.

\section{The persistence of car ownership in the United States}

The rate of car ownership among US households has remained over $90 \%$ for the past decade ${ }^{19}$, supported by socioeconomic trends including greater workforce participation and rising incomes ${ }^{20-22}$, urban sprawl and low-density suburban development ${ }^{20-24}$, and ample, cheap road and parking supply ${ }^{25-27}$.

Various studies have predicted the demise of privately owned vehicles with generational and demographic changes, pointing to lower rates of driver licensing and car ownership among young people $\mathrm{e}^{28-32}$. However, recent studies find little difference in preferences for car ownership between Millennials and previous generations after accounting for their different socioeconomic circumstances ${ }^{33-36}$. New on-demand travel options such as ride-hailing and mobility-as-a-service apps (also known as MaaS apps, digital platforms that allow people to seamlessly plan, book and pay for multiple mobility services) have also garnered attention

'Mobility Systems Center, MIT Energy Initiative, Cambridge, MA, USA. ${ }^{2}$ Department of Urban Studies and Planning, Massachusetts Institute of Technology, Cambridge, MA, USA. ${ }^{3}$ Wellesley College, Wellesley, MA, USA. ${ }^{4}$ Sloan School of Management, Massachusetts Institute of Technology, Cambridge, MA, USA. ${ }^{\circledR e}$-mail: dkeith@mit.edu 
Table 1 | Base model estimation results (with standard errors) and calculated median WTAC to lose access to a transportation option for a typical year and for a month during COVID-19

\begin{tabular}{|c|c|c|c|c|c|}
\hline Framing & Scenario & Random intercept & Coefficient of $\log (C)$ & $\begin{array}{l}\text { Median WTAC best } \\
\text { estimate (and } 95 \% \mathrm{Cl} \text { ) }\end{array}$ & $\begin{array}{l}\text { Median WTAC for a typical } \\
\text { month (year estimate/12) }\end{array}$ \\
\hline \multirow{4}{*}{$\begin{array}{l}\text { Typical year } \\
\text { (pre-COVID-19) }\end{array}$} & 1. Ride-hailing ${ }^{\mathrm{a}}$ & $-3.66(0.14)$ & $0.76(0.02)$ & $\$ 123(\$ 98, \$ 149)$ & $\$ 10$ \\
\hline & $\begin{array}{l}\text { 2. Car ownership and } \\
\text { use }^{b}\end{array}$ & $-10.43(0.24)$ & $1.12(0.03)$ & $\begin{array}{l}\$ 11,197(\$ 9,908 \\
\$ 12,648)\end{array}$ & $\$ 933$ \\
\hline & 3. Car ownership only & $-10.39(0.25)$ & $1.18(0.03)$ & $\$ 6,496(\$ 5,706, \$ 7,377)$ & $\$ 541$ \\
\hline & Car use only (calculated) & - & - & $\$ 4,701$ & $\$ 392$ \\
\hline \multirow{4}{*}{$\begin{array}{l}\text { Month during } \\
\text { COVID-19 }\end{array}$} & 1. Ride-hailinga & $-1.49(0.11)$ & $0.64(0.02)$ & $\$ 10(\$ 7, \$ 14)$ & - \\
\hline & $\begin{array}{l}\text { 2. Car ownership and } \\
\text { use }^{b}\end{array}$ & $-8.13(0.22)$ & $1.00(0.03)$ & $\$ 3,361(\$ 2,736, \$ 4,173)$ & - \\
\hline & 3. Car ownership only & $-7.46(0.21)$ & $0.93(0.03)$ & $\$ 2,960(\$ 2,376, \$ 3,726)$ & - \\
\hline & Car use only (calculated) & - & - & $\$ 401$ & - \\
\hline
\end{tabular}

All estimated coefficients were statistically different from zero at a 0.01 level; $95 \%$ confidence interval $(\mathrm{Cl})$ calculated using 1,000 bootstrapping iterations, with each iteration randomly selecting 1,500

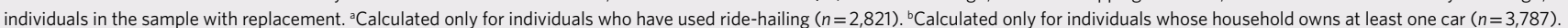

as potential alternatives to the privately owned cars in US $\operatorname{cities}^{37-40}$. While some studies have found that ride-hailing services do have a significant impact on reducing car ownership at various scales ${ }^{41-45}$, more-recent longitudinal analyses have found that the introduction of ride-hailing services has had little effect on vehicle ownership across the United States, except in cities with the most-robust transit systems ${ }^{46}$.

In this study, we frame our valuation questions as the compensation that a respondent would be willing to accept to give up their private car, recognizing that this framing introduces the endowment effect ${ }^{47}$ because the reality is that the majority of Americans already own a car.

\section{Results}

On the basis of survey data in our four target US cities, we find the following from our single binary discrete choice (SBDC) and bestworst scaling (BWS) experiments:

1. On average, private cars are valued more than they cost, and the majority of that value comes from ownership rather than use.

2. During the COVID-19 pandemic, the value of car ownership increased dramatically, but the value of car use did not.

3. Individuals who travel less by car and more by other modes are more willing to give up private car ownership and use.

4. The value of private car ownership and use is lower for urban residents, independent of the metropolitan area they live in.

5. The value of car ownership and use is orders of magnitude higher than the value of other urban transportation options.

People value car ownership and use more than they cost. From our SBDC experiment, we find that people value owning and using their car annually at $\$ 11,197$ on average (Table 1, top panel), significantly more than the American Automobile Association's reported average annual cost of owning and using a car of $\$ 9,282$ $\left(\right.$ ref. ${ }^{2}$ ). If anything, these estimates are likely to be conservative; incorporating sample weights to control for underrepresentation of certain sociodemographic groups in the sample results in slightly higher but consistent median estimates for willingness to accept compensation (WTAC) (see details in Supplementary Information Section 2.3)

This finding runs counter to the narrative that people are behaving irrationally by owning a car because they underestimate the true cost. Instead, we find that people value owning the car high enough to make the private cost worthwhile. Indeed, $58 \%$ of this value is in owning the car, compared with $42 \%$ in using it, suggesting that the value of the car goes well beyond the trips that it provides. When asked to select the most important reasons that they might be reluctant to give up their car, our respondents most commonly cited control over travel schedule, certainty and reliability, and flexibility, which all make up some aspect of 'option value,' or the value placed on having the car available to use whenever it is needed (Supplementary Fig. 5).

The value of car ownership increased during the COVID-19 pandemic. In addition to asking respondents their preferences during a pre-COVID-19 year, such as 2019, we asked respondents their preferences for one month during the pandemic. We find that people's valuation of owning and using a car increased by $260 \%$ during a pandemic month (to $\$ 3,361$ ) compared with a month pre-pandemic (approximately \$933) (Table 1, bottom panel). The majority of this increase is in the value of owning a car, rather than using it, with the use component very similar during the pandemic ( $\$ 401$ per month) to what it was pre-pandemic (\$392 per month). This result probably reflects the control and flexibility that car ownership provides at a time when there is substantial fear and uncertainty about viral transmission, such as the ability to travel out of COVID-19 hotspots or to visit supermarkets or medical facilities without using shared modes. We caution that our responses were collected during the first wave of the COVID-19 pandemic when disruptions to everyday life (including travel) were particularly salient, and uncertainties surrounding the nature and impact of the virus remained high. Nevertheless, the stark finding that car ownership value increased during the pandemic highlights the importance of option value as a key incentive for car ownership. In times of greater uncertainty, when consumers are more likely to be risk averse, car ownership is a security blanket, and its option value is an especially salient feature in consumer decision-making.

People who travel less by car are more willing to give up car ownership. In this and the following section, we consider how differences in individuals' willingness to give up their car at a given compensation level is explained by factors such as travel behaviour, built environment and employee benefits (Table 2).

We find that an individual's typical travel behaviour helps explain their choice to give up access to their private car at a given compensation level. Individuals who take more trips by car in a typical week are less willing to give up their private car under current conditions (Scenario 2 in Table 2), but this effect goes away if individuals can 


\begin{tabular}{|c|c|c|c|}
\hline Predictor & Scenario 1 (ride-hailing) & Scenario 2 (vehicle ownership and use) & Scenario 3 (vehicle ownership) \\
\hline Random intercept & $-2.71(0.38)^{* \ldots+}$ & $-10.30(0.37)^{\ldots * *}$ & $-10.00(0.42)^{\ldots * *}$ \\
\hline $\log ($ compensation) & $0.76(0.02)^{* * *}$ & $1.12(0.025)^{* * x}$ & $1.19(0.03)^{* * *}$ \\
\hline Rural (0/1) & $0.12(0.26)$ & $-0.14(0.17)$ & $-0.20(0.20)$ \\
\hline Urban $(0 / 1)$ & $-0.45(0.13)^{\ldots * *}$ & $0.17(0.10)^{*}$ & $0.14(0.12)$ \\
\hline Washington DC (0/1) & $-0.04(0.16)$ & $0.02(0.13)$ & $0.36(0.15)^{* *}$ \\
\hline Chicago $(0 / 1)$ & $0.11(0.16)$ & $-0.14(0.13)$ & $0.10(0.15)$ \\
\hline Seattle $(0 / 1)$ & $-0.01(0.17)$ & $-0.07(0.13)$ & $0.23(0.15)$ \\
\hline Male (0/1) & $-0.09(0.12)$ & $0.42(0.10)^{n * *}$ & $0.12(0.12)$ \\
\hline Age (years) & $0.01(0.00)^{* *}$ & $-0.02(0.00)^{* * *}$ & $-0.03(0.00)^{\ldots * *}$ \\
\hline Black (0/1) & $-0.42(0.19)^{* *}$ & $0.39(0.16)^{* *}$ & $0.37(0.19)^{*}$ \\
\hline Hispanic $(0 / 1)$ & $-0.17(0.20)$ & $0.43(0.17)^{* *}$ & $0.26(0.20)$ \\
\hline Other non-white race $(0 / 1)^{a}$ & $-0.43(0.16)^{x * *}$ & $0.28(0.13)^{* * *}$ & $0.33(0.16)^{* *}$ \\
\hline College degree $(0 / 1)$ & $-0.61(0.15)^{* * *}$ & $-0.14(0.11)$ & $-0.01(0.13)$ \\
\hline Advanced degree $(0 / 1)$ & $-0.31(0.17)^{*}$ & $0.10(0.14)$ & $0.09(0.16)$ \\
\hline Full-time employed (0/1) & $-0.08(0.15)$ & $0.04(0.12)$ & $0.15(0.14)$ \\
\hline Unemployed $(0 / 1)$ & $0.12(0.21)$ & $0.47(0.15)^{* * *}$ & $0.47(0.18)^{* *}$ \\
\hline Student & $-0.21(0.27)$ & $0.03(0.23)$ & $0.32(0.27)$ \\
\hline Household income $(\$ 1,000)$ & $-0.00(0.00)^{\ldots *}$ & $-0.00(0.00)$ & $-0.00(0.00)$ \\
\hline Household children (no.) & $-0.10(0.06)$ & $0.07(0.05)$ & $-0.02(0.06)$ \\
\hline Household working adults (no.) & $0.03(0.07)$ & $-0.02(0.05)$ & $-0.00(0.06)$ \\
\hline Zero-car household (0/1) & $-1.23(0.26)^{\ldots *}$ & - & - \\
\hline One-car household (0/1) & $-0.43(0.14)^{x * *}$ & $0.31(0.11)^{* * *}$ & $0.35(0.13)^{x \star *}$ \\
\hline Weekly trips by car (no.) & $0.00(0.00)$ & $-0.01(0.00)^{* \star \star}$ & $-0.00(0.00)$ \\
\hline Weekly trips by ride-hailing (no.) & $-0.04(0.01)^{n * *}$ & $0.02(0.01)^{* *}$ & $0.01(0.01)$ \\
\hline Weekly trips by PT (no.) & $0.02(0.01)^{* *}$ & $0.02(0.01)^{* *}$ & $0.01(0.01)$ \\
\hline Weekly trips by NMT (no.) & $-0.01(0.01)$ & $0.02(0.00)^{* * *}$ & $0.02(0.01)^{n * *}$ \\
\hline Unable to use car $(0 / 1)$ & $-0.20(0.15)$ & $0.38(0.13)^{* *}$ & $0.03(0.15)$ \\
\hline Free parking $(0 / 1)$ & $-0.12(0.13)$ & $-0.02(0.11)$ & $-0.03(0.13)$ \\
\hline Carpool programme $(0 / 1)$ & $-0.00(0.21)$ & $0.35(0.18)^{* *}$ & $0.30(0.21)$ \\
\hline Subsidized PT (0/1) & $-0.07(0.16)$ & $0.35(0.15)^{* *}$ & $0.39(0.17)^{* *}$ \\
\hline Bike facilities (0/1) & $0.17(0.22)$ & $0.16(0.19)$ & $0.63(0.22)^{* * *}$ \\
\hline
\end{tabular}

ather non-white race includes Asian, American Indian or Alaska Native, and Native Hawaiian or other Pacific Islander. No., number; PT, public transport; NMT, non-motorized transport; -, not applicable; ${ }^{\star \star \star} P<0.01 ;{ }^{* \star} P<0.05 ;{ }^{*} P<0.1$.

replace use of their car with unlimited ride-hailing trips (Scenario 3 in Table 2). We also find that individuals who make more trips by modes other than the private car-including public transit, walking, biking or ride-hailing-are more likely to give up access to their car under current conditions. This might suggest that the value that car-dependent Americans place on car ownership may differ meaningfully to values that exist in Europe and other regions ${ }^{48}$. People who receive a free or subsidized transit pass, a carpool benefit or bike facilities from their employer are more willing to give up their car (Scenarios 2 and 3), suggesting that incentivizing people to use alternative modes of travel to work could be impactful in reducing car ownership.

The value of car ownership and use is lower for urban residents. We find that the built environment where a person lives meaningfully impacts their valuation of owning and using a car. Living in an urban zip code is positively correlated with being more willing to give up one's car as compared with living in a rural or suburban zip code. Each increase in the built environment category, which aggregates many elements of the built environment that may have varying significance individually (for example, density, mix of uses, supply of parking, density of street network, biking infrastructure and public transit infrastructure), reduced the median value of owning and using a car by nearly $\$ 4,000$. Importantly, once this built environment variable was added to the model, the impact of each of the city dummy variables became insignificant, suggesting that the built environment has a bigger impact than region-specific geographic, cultural or governance differences. This finding is in line with previous research that found car use is more dependent on local rather than city-wide characteristics ${ }^{49}$.

The value of other urban transportation modes is much lower. Our BWS results are broadly consistent with the results of our SBDC responses, ranking the disutility of not having access to a personal car for a year between the disutility of earning $\$ 10,000$ less for a year and that of earning $\$ 20,000$ less for a year (Fig. 1). By contrast, 


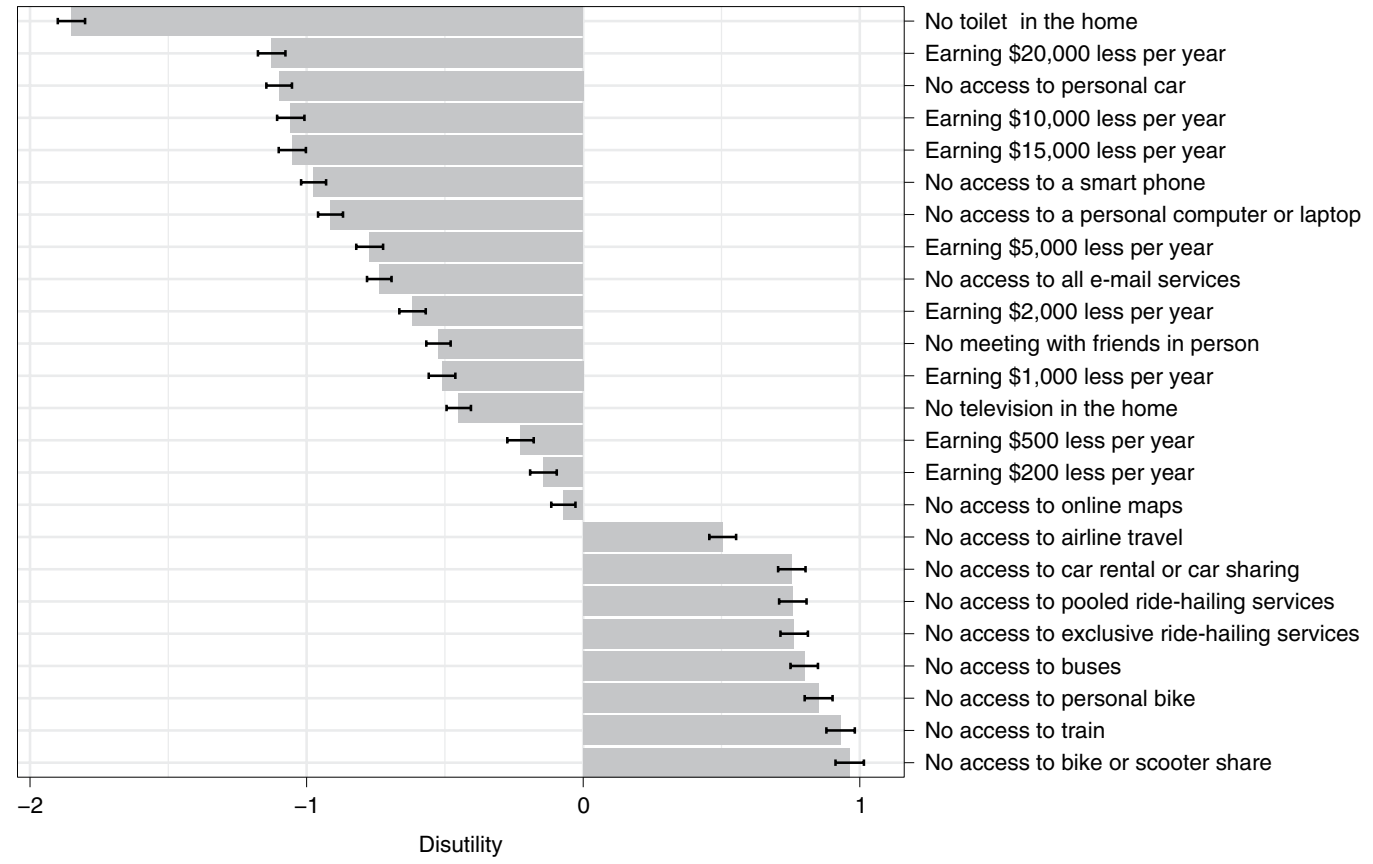

Fig. 1 | Disutility of losing an option for a year based on BWS maxdiff model estimation; all results are relative to earning $\$ 100$ less per year set to disutility $=0$. Values indicate estimated coefficient; error bars indicate \pm one standard error around that estimate.

access to other mobility options, including airline travel, car rental, ride-hailing, public transit and bikes/scooters, is valued at less than $\$ 100$ for a year.

Using the estimated disutilities of the monetary loses, we can estimate monetary values for the mobility and non-mobility options (Supplementary Information). We find that the value of one year of access to a personal car is estimated to be $\$ 16,890$. Access to all other forms of transportation included among the mobility options-car rental or car sharing, exlcusive or pooled ride-hailing services, bus, train, and personal bike or bike/scooter share-was valued under $\$ 5$ per option. These extremely low valuations of individual non-car mobility goods is notable considering the energy behind MaaS, or a package of non-car mobility goods, replacing car ownership. The sum of valuations of these goods remains below $\$ 50$, which is unlikely to compete with the value of a personal car. If MaaS is to compete with private car ownership, the packaging of these mobility goods must result in a value much greater than the sum of its parts.

\section{Discussion}

While it may be true that people underestimate the true cost of car ownership and use, they are not 'irrationally' buying cars. Instead, consumers own and use vehicles because the vehicles' perceived value more than accounts for the incurred private cost, with a major fraction of this value derived from the control, certainty, reliability and flexibility that car ownership provides. While undertaking this study during the COVID-19 pandemic unavoidably introduced questions about how our results generalize, it has also helped to reinforce our findings regarding the importance of option value from car ownership. We measure a significant increase in the value of car ownership (but not use) in our during-pandemic scenario, consistent with the control, certainty and flexibility ownership provided during a period of great uncertainty.

Our results contribute to our understanding of why patterns of car ownership and use in the United States are so persistent and provide hints as to what interventions might steer people away from car ownership. People value owning a car less when they have good-quality, non-private-car alternatives such as public transit, walking and biking, and employer-benefits programmes can help. However, the reality is that the average value of car ownership and use is at least an order of magnitude higher than the value of other urban transportation options, including ride-hailing, public transportation and non-motorized transport. The challenge for policymakers, researchers and mobility companies, then, is to identify packages of urban transportation alternatives that together can provide value that rivals that of the private car, even when each non-car component of such a multimodal offering is not valued highly.

The issues raised in this study, and limitations of existing approaches, give rise to many important research opportunities. Our findings suggest that existing studies of mode choice undertaken on a trip-by-trip basis (often with a focus on cost per mile) are unlikely to capture the full value of the car in terms of the lifestyle and options it enables. Future research should expand beyond the trip level to consider whether packages of non-private car mobility goods (for example, the MaaS schemes described) can provide sufficient value to the point of being competitive with the value of car ownership. Recent work by Guidon et al..$^{50}$ found that willingness to pay for packages of services was higher than for unpackaged stand-alone services, and more work is needed mimicking the system-level features of car ownership that people value using features such as guaranteed wait times, guaranteed travel times and extended hours of operation. Finally, the transition to more sustainable and shared transportation modes (including nascent technologies such as autonomous vehicles) will require millions of people to give up private vehicle ownership in its current form. Future studies should explicitly frame studies of MaaS adoption with reference to private car ownership if we are to effectively elicit the design of compelling alternatives.

\section{Methods}

We undertook an online survey with two types of discrete choice experiments: SBDC $^{51}$ and BWS ${ }^{52}$. These stated choice experiments are designed to measure the 'perceived' value that an individual places on access to a transportation mode rather than the 'market' value (or price) of the mode or vehicle.

Here we introduce our respondent recruitment and our two choice experiments. For additional details on sample representativeness, survey design and estimation methods, refer to the Supplementary Information. 
Sample. We implemented our study in four metropolitan areas of the United States-Washington DC, Chicago, Seattle and Dallas-chosen to provide variation in factors such as geography and transit availability. We recruited participants to take our online survey between June 10 and July 2, 2020, using Qualtrics, a professional panel company. Quota sampling was used to ensure statistical representativeness of each metropolitan area sample by age, household income and household car ownership. A total of 4,937 responses were collected, from which 915 individuals were screened out by quota questions or failed to complete all sections of the survey. This left us with a final sample size of 4,022 responses, with 1,017 from Washington DC, 1,006 from Chicago, 1,001 from Seattle and 998 from Dallas.

Despite the use of quotas in each of our metropolitan areas, we find that our online sample overrepresents individuals with high educational attainment (advanced degrees) compared with those who attained no more than a high school diploma. Households with low and high income, with only one person or with three or more vehicles also appear to be undersampled. To explore the impact of this non-representativeness of sample, we also estimated models incorporating sample weights. These results are presented and discussed in Section 2.3 of the Supplementary Information but are largely consistent with the unweighted model results shown in this manuscript; if anything, the weighted results suggest that our estimates of the value of transport access here are slightly conservative.

Single binary discrete choice. The SBDC experiment asked respondents to make a single choice from two options: keep access to a transportation option or forgo access in return for receiving a specific amount of compensation. Different scenarios were created to measure the value of private car ownership and use compared with ride-hailing:

1. Value of ride-hailing: given all your travel needs and options, choose whether to give up access to ride-hailing for one year and receive a compensation amount, or keep access to ride-hailing and receive no compensation.

2. Value of car ownership and use: given all your travel needs and options, choose whether to give up access to your primary car for one year and receive a compensation amount, or keep access to your car and receive no compensation.

3. Value of car ownership: you are given access to a new, free, ubiquitously available ride-hailing service that can serve all of the trips that you currently make by your primary vehicle without any additional inconvenience. Choose whether to give up access to your primary car for one year and receive this free service and a compensation amount, or keep access to your car and receive neither compensation nor free ride-hailing.

From the difference between scenarios 2 and 3, we can isolate the value of car use. Respondents who indicated they did not own a car were presented only with Scenario 1. Respondents who had not used ride-hailing before were not presented with Scenario 1 . The full questionnaire is provided at the end of the Supplementary Information (Section 4).

Each respondent was randomly presented with four compensation amounts for each scenario. For one set of scenarios, respondents were asked to recall their typical travel behaviour in a year pre-COVID-19 (for example, 2019). For a second set of scenarios, respondents were asked to answer for a month during COVID-19, with the monetary amounts adjusted to be approximately $1 / 12$ th those provided for the typical year.

For each SBDC scenario, we estimate a binary logistic regression model that includes a random intercept and the log of the compensation amount, $C$, displayed in each choice experiment. Setting the probability of giving up the car (or ride-hailing) equal to 0.5 , we can solve for the median WTAC. This provides a point estimate of the compensation amount associated with indifference between giving up and keeping access to the car (or ride-hailing) for the entire sample. We also estimate this model with additional covariates, including the individual's typical travel behaviour, household and individual demographic characteristics, the built environment of their residence and the employee benefits that they receive. On the basis of the estimated coefficients and the observed values of the covariates we can then calculate individual-specific indifference compensation amounts $\left(C_{\mathrm{i}}\right)$. This allows us to explore heterogeneity in WTAC across our sample of respondents (Supplementary Information Section 2.2).

As an additional robustness check to ensure that respondent heterogeneity is appropriately captured in our SBDC models, we estimate models with a random coefficient for the compensation amount (in addition to a random intercept). These models show no improvement in model fit or substantial change in estimated median WTAC.

Best-worst scaling. While the main results of this study come from these SBDC experiments, we also employed BWS as a benchmarking method following Brynjolfsson, Collis and Eggers ${ }^{53}$. Employing a case 1 or object-case BWS design, we asked respondents to select the best (most important) and worst (least important) from a set of three options: a mobility good, a non-mobility good and a monetary amount ${ }^{54}$. Respondents answered ten randomly allocated BWS choice questions and were randomly assigned to either pre- or during-COVID-19 framings for the questions. Utility parameters for the BWS experiment were estimated using a random intercept multinomial logit with maxdiff model ${ }^{54}$.
Following instructions, each respondent received ten BWS questions, each with a randomly generated mobility good, non-mobility good and monetary amount. See Supplementary Information Sections 3.1 and 3.2 for full details on the BWS experimental design and screenshots of the survey interface.

Reporting Summary. Further information on research design is available in the Nature Research Reporting Summary linked to this article.

\section{Data availability}

The data that support the findings of this study are available on request from the corresponding author. The data are not publicly available because they contain information that could compromise research participant privacy/consent.

\section{Code availability}

The full questionnaire, analysis code and results are available at https://github. $\mathrm{com} / \mathrm{jcmoody} 6 /$ car-value. Correspondence and requests for materials should be addressed to the corresponding author.

Received: 3 December 2020; Accepted: 10 May 2021; Published online: 17 June 2021

\section{References}

1. Household, Individual, and Vehicle Characteristics (Bureau of Transportation Statistics, 2017); https://www.bts.gov/archive/publications/highlights_of_ the 2001 national household travel survey/section 01

2. Edmonds, E. 2019 Your Driving Costs: Spike in Finance Costs Drives Increase (AAA, 2019); https://newsroom.aaa.com/2019/09/ your-driving-costs-spike-in-finance-costs-drives-increase

3. Shaheen, S. in Three Revolutions (ed. Sperling, D.) 55-76 (Island Press, 2018)

4. Manville, M. \& Shoup, D. Parking, people, and cities. J. Urban Plan. Dev. 131 233-245 (2005).

5. Shoup, D. C. The high cost of free parking. J. Plan. Educ. Res. 17, 3-20 (1997).

6. Andor, M. A., Gerster, A., Gillingham, K. T. \& Horvath, M. Running a car costs much more than people think-stalling the uptake of green travel. Nature 580, 453-455 (2020).

7. Wilhelms, M.-P., Henkel, S. \& Falk, T. To earn is not enough: a means-end analysis to uncover peer-providers' participation motives in peer-to-peer carsharing. Technol. Forecast. Soc. Change 125, 38-47 (2017).

8. Duncan, M. The cost saving potential of carsharing in a US context. Transportation 38, 363-382 (2011).

9. Shafir, E. \& Thaler, R. H. Invest now, drink later, spend never: on the mental accounting of delayed consumption. J. Econ. Psychol. 27, 694-712 (2006).

10. Millard-Ball, A., Murray, G., Schure, J. T., Fox, C. \& Burkhardt, J. Car Sharing: Where and How it Succeeds Report 108 (Transportation Research Board, 2005).

11. Katzev, R. Car sharing: a new approach to urban transportation problems. Anal. Soc. Issues Public Policy 3, 65-86 (2003).

12. Curl, A., Clark, J. \& Kearns, A. Household car adoption and financial distress in deprived urban communities: a case of forced car ownership? Transp. Policy 65, 61-71 (2018).

13. Blumenberg, E. \& Pierce, G. Car access and long-term poverty exposure: evidence from the Moving to Opportunity (MTO) experiment. J. Transp. Geogr. 65, 92-100 (2017).

14. Gurley, T. \& Bruce, D. The effects of car access on employment outcomes for welfare recipients. J. Urban Econ. 58, 250-272 (2005).

15. Moody, J. \& Zhao, J. Travel behavior as a driver of attitude: car use and car pride in US cities. Transp. Res. Part F 47, 225-236 (2020).

16. Moody, J. \& Zhao, J. Car pride and its bidirectional relations with car ownership: case studies in New York City and Houston. Transp. Res. Part A 124, 334-353 (2019).

17. Steg, L. Car use: lust and must. Instrumental, symbolic and affective motives for car use. Transp. Res. Part A 39, 147-162 (2005).

18. Prettenthaler, F. E. \& Steininger, K. W. From ownership to service use lifestyle: the potential of car sharing. Ecol. Econ. 28, 443-453 (1999).

19. Means of Transportation to Work by Vehicles Available Table B08141 (US Census Bureau, 2020); https://data.census.gov/cedsci/table?text=B08141\&t=Tr ansportation $\& y=2010 \&$ tid $=$ ACSDT5Y2010.B08141 \&hidePreview $=$ false

20. Oakil, A. T. M., Manting, D. \& Nijland, H. Determinants of car ownership among young households in the Netherlands: the role of urbanisation and demographic and economic characteristics. J. Transp. Geogr. 51, 229-235 (2016)

21. Clark, B., Lyons, G. \& Chatterjee, K. Understanding the process that gives rise to household car ownership level changes. J. Transp. Geogr. 55, 110-120 (2016).

22. Bhat, C. R. \& Guo, J. Y. A comprehensive analysis of built environment characteristics on household residential choice and auto ownership levels. Transp. Res. Part B 41, 506-526 (2007). 
23. Axsen, J., Plötz, P. \& Wolinetz, M. Crafting strong, integrated policy mixes for deep $\mathrm{CO}_{2}$ mitigation in road transport. Nat. Clim. Change 10, 809-818 (2020).

24. Stevens, M. R. Does compact development make people drive less? J. Am. Plan. Assoc. 83, 7-18 (2017).

25. Guo, Z. Does residential parking supply affect household car ownership? The case of New York City. J. Transp. Geogr. 26, 18-28 (2013).

26. Buehler, R. Transport policies, automobile use, and sustainable transport: a comparison of Germany and the United States. J. Plan. Educ. Res. 30, 76-93 (2010).

27. Shoup, D. C. The ideal source of local public revenue. Reg. Sci. Urban Econ. 34, 753-784 (2004)

28. Ho, C. Q., Hensher, D. A., Mulley, C. \& Wong, Y. Z. Potential uptake and willingness-to-pay for mobility as a service (MaaS): a stated choice study. Transp. Res. Part A 117, 302-318 (2018).

29. Hjorthol, R. Decreasing popularity of the car? Changes in driving licence and access to a car among young adults over a 25 -year period in Norway. $J$. Transp. Geogr. 51, 140-146 (2016).

30. McDonald, N. C. Are Millennials really the 'go-nowhere' generation? J. Am. Plan. Assoc. 81, 90-103 (2015).

31. Delbosc, A. \& Currie, G. Causes of youth licensing decline: a synthesis of evidence. Transp. Rev. 33, 271-290 (2013).

32. Kuhnimhof, T., Buehler, R. \& Dargay, J. A new generation: travel trends for young Germans and Britons. Transp. Res. Rec. 1989, 58-67 (2011).

33. Etezady, A., Shaw, F. A., Mokhtarian, P. L. \& Circella, G. What drives the gap? Applying the Blinder-Oaxaca decomposition method to examine generational differences in transportation-related attitudes. Transportation https://doi. org/10.1007/s11116-020-10080-5 (2020).

34. Knittel, C. \& Murphy, E. Generational Trends in Vehicle Ownership and Use: Are Millennials Any Different? Working Paper 25674 (National Bureau of Economic Research, 2019); https://doi.org/10.3386/w25674

35. Kurz, C., Li, G. \& Vine, D. J. 2018. Are Millennials Different? Finance and Economics Discussion Series 2018-080 (Board of Governors of the Federal Reserve System, 2018); https://doi.org/10.17016/FEDS.2018.080

36. Klein, N. J. \& Michael, J. S. Millennials and car ownership: less money, fewer cars. Transp. Policy 53, 20-29 (2017).

37. Lyons, G., Hammond, P. \& Mackay, K. The importance of user perspective in the evolution of MaaS. Transp. Res. Part A 121, 22-36 (2019).

38. Mulley, C. Mobility as a service (MaaS) - does it have critical mass? Transp. Rev. 37, 247-251 (2017).

39. Jittrapirom, P. et al. Mobility as a service: a critical review of definitions, assessments of schemes, and key challenges. Urban Plan. 2, 13-25 (2017).

40. Eckhardt, J., Aapaoja, A., Nykänen, L. \& Sochor, J. Mobility as a service business and operator models. In Proc. 12th ITS European Congress 19-22 (2017).

41. Bansal, P., Sinha, A., Dua, R. \& Daziano, R. A. Eliciting preferences of TNC users and drivers: evidence from the United States. Travel Behav. Soc. 20, 225-236 (2020).

42. Schaller, B. The New Automobility: Lyft, Uber, and the Future of American Cities (Schaller Consulting, 2018); http://www.schallerconsult.com/ rideservices/automobility.htm

43. Hampshire, R. C., Simek, C., Fabusuyi, T., Di, X. \& Chen, X. Measuring the impact of an unanticipated suspension of ride-sourcing in Austin, Texas. SSRN Electron. J. (2017).

44. Gehrke, S. R., Felix, A. \& Reardon, T. Fare Choices: A Survey of Ride-Hailing Passengers in Metro Boston (Metropolitan Area Planning Council, 2018); https://www.mapc.org/farechoices/
45. Rayle, L., Dai, D., Chan, N., Cervero, R. \& Shaheen, S. Just a better taxi? A survey-based comparison of taxis, transit, and ridesourcing services in San Francisco. Transp. Policy 45, 168-178 (2016).

46. Diao, M., Kong, H. \& Zhao, J. Impacts of transportation network companies on urban mobility. Nat. Sustain. https://doi.org/10.1038/s41893-020-00678-Z (2021).

47. Knetsch, J. L. The endowment effect and evidence of nonreversible indifference curves. Am. Econ. Rev. 79, 1277-1284 (1989).

48. Ashmore, D. P., Thoreau, R., Kwami, C., Christie, N. \& Tyler, N. A. Using thematic analysis to explore symbolism in transport choice across national cultures. Transportation 47, 607-640 (2020).

49. Klinger, T. \& Lanzendorf, M. Moving between mobility cultures: what affects the travel behavior of new residents? Transportation 43, 243-271 (2016).

50. Guidon, S., Wicki, M., Bernauer, T. \& Axhausen, K. Transportation service-for whose benefit? Consumer valuation of pure bundling in the passenger transportation market. Transp. Res. Part A 131, 91-106 (2020).

51. Loomis, J., Peterson, G., Champ, P., Brown, T. \& Lucero, B. Paired comparison estimates of willingness to accept versus contingent valuation estimates of willingness to pay. J. Econ. Behav. Organ. 35, 501-515 (1998)

52. Louviere, J., Lings, I., Islam, T., Gudergan, S. \& Flynn, T. An introduction to the application of (case 1) best-worst scaling in marketing research. Int. J. Res. Mark. 30, 292-303 (2013)

53. Brynjolfsson, E., Collis, A. \& Eggers, F. Using massive online choice experiments to measure changes in well-being. Proc. Natl Acad. Sci. USA 116 7250-7255 (2019).

54. Louviere, J. J., Flynn, T. N. \& Marley, A. A. J. Best-Worst Scaling: Theory, Methods and Applications (Cambridge Univ. Press, 2015).

\section{Acknowledgements}

This research was funded by an MIT Energy Initiative's Mobility Systems Center project grant awarded to D.R.K. and J.M.

\section{Author contributions}

J.M. and D.R.K. developed the original research question; J.M., E.F. and D.R.K. designed the questionnaire and stated preference experiments; J.M., E.F. and M.P. oversaw data collection and undertook data analysis; J.M., E.F. and D.R.K. wrote and revised the manuscript.

\section{Competing interests}

The authors declare no competing interests.

\section{Additional information}

Supplementary information The online version contains supplementary material available at https://doi.org/10.1038/s41893-021-00731-5.

Correspondence and requests for materials should be addressed to D.R.K.

Peer review information Nature Sustainability thanks Sonja Haustein, Rico Krueger and the other, anonymous, reviewer(s) for their contribution to the peer review of this work.

Reprints and permissions information is available at www.nature.com/reprints. Publisher's note Springer Nature remains neutral with regard to jurisdictional claims in published maps and institutional affiliations.

(c) The Author(s), under exclusive licence to Springer Nature Limited 2021 


\section{Reporting Summary}

Nature Research wishes to improve the reproducibility of the work that we publish. This form provides structure for consistency and transparency in reporting. For further information on Nature Research policies, see our Editorial Policies and the Editorial Policy Checklist.

\section{Statistics}

For all statistical analyses, confirm that the following items are present in the figure legend, table legend, main text, or Methods section.

n/a Confirmed

\The exact sample size $(n)$ for each experimental group/condition, given as a discrete number and unit of measurement

Х $\square$ A statement on whether measurements were taken from distinct samples or whether the same sample was measured repeatedly

The statistical test(s) used AND whether they are one- or two-sided

Only common tests should be described solely by name; describe more complex techniques in the Methods section.

$\bigotimes$ A description of all covariates tested

Х $\square$ A description of any assumptions or corrections, such as tests of normality and adjustment for multiple comparisons

$\triangle$ A full description of the statistical parameters including central tendency (e.g. means) or other basic estimates (e.g. regression coefficient)

AND variation (e.g. standard deviation) or associated estimates of uncertainty (e.g. confidence intervals)

$\varnothing$ For null hypothesis testing, the test statistic (e.g. $F, t, r$ ) with confidence intervals, effect sizes, degrees of freedom and $P$ value noted Give $P$ values as exact values whenever suitable.

Х $\square$ For Bayesian analysis, information on the choice of priors and Markov chain Monte Carlo settings

Х $\square$ For hierarchical and complex designs, identification of the appropriate level for tests and full reporting of outcomes

Х $\square$ Estimates of effect sizes (e.g. Cohen's $d$, Pearson's $r$ ), indicating how they were calculated

Our web collection on statistics for biologists contains articles on many of the points above.

\section{Software and code}

Policy information about availability of computer code

Data collection The survey was implemented using the Qualtrics platform. The complete questionnaire (as an exported pdf) and the data dictionary (including description of all available covariates) are available at https://github.com/jcmoody6/car-value.

Data analysis Data cleaning and base model analysis was performed in R (open source). Robustness checks incorporating survey weights and random coefficients for compensation amount were performed in Mplus, version 8.1. Input code and output files for all analyses are available at https://github.com/jcmoody6/car-value.

For manuscripts utilizing custom algorithms or software that are central to the research but not yet described in published literature, software must be made available to editors and reviewers. We strongly encourage code deposition in a community repository (e.g. GitHub). See the Nature Research guidelines for submitting code \& software for further information.

\section{Data}

Policy information about availability of data

All manuscripts must include a data availability statement. This statement should provide the following information, where applicable:

- Accession codes, unique identifiers, or web links for publicly available datasets

- A list of figures that have associated raw data

- A description of any restrictions on data availability

The data that support the findings of this study are available on request from the corresponding author. The data are not publicly available due to them containing information that could compromise research participant privacy/consent. 


\section{Field-specific reporting}

Please select the one below that is the best fit for your research. If you are not sure, read the appropriate sections before making your selection.

Life sciences

$\bigotimes$ Behavioural \& social sciences

Ecological, evolutionary \& environmental sciences

For a reference copy of the document with all sections, see nature.com/documents/nr-reporting-summary-flat.pdf

\section{Behavioural \& social sciences study design}

All studies must disclose on these points even when the disclosure is negative.

Study description

Online survey with two types of discrete choice experiments: single binary discrete choice (SBDC) and best-worst scaling (BWS)

Research sample

Respondents were recruited from four metropolitan areas of the U.S.: Washington, D.C., Chicago, Seattle, and Dallas. Self-reported home zip codes of respondents were screened to ensure that individuals in the sample lived in one of the target metropolitan statistical areas (as defined by the U.S. census). The 4 metropolitan areas were chosen to provide variation in terms of urban built environment, geography, transit availability, and existing levels of car ownership and car use for commuting (according to census data). Despite the use of quotas in each of our metropolitan areas, we find that our online sample over-represents individuals with high educational attainment (advanced degrees) compared to those who attained no more than a high school diploma. Households with low and high income, only one person, or with three or more vehicles also appear to be under-sampled. To explore the impact of this non-representativeness of sample, we also estimated models incorporating sample weights. These results are presented and discussed in Section 2.3 of the Supplemental Information (SI), but are largely consistent with the unweighted model results shown in the main manuscript.

Sampling strategy

Quota sampling was used to ensure statistical representativeness of each metropolitan area sample by age, household income, and household car ownership. However, towards the end of data collection, quotas were relaxed for the highest car ownership and lowest income categories due to lagging response rates. Sample sizes of 1000 respondents per metropolitan area were determined to be more than adequate given preliminary power analyses for both SBDC and BWS experiments (balanced with the number of choices provided to each respondent).

Data collection Data was collected using an online survey. Participants voluntarily completed the survey from a recruitment link (distributed to the target metropolitan populations by a professional panel company, Qualtrics). Participants were given simple instructions that laid out the general aim of the research, without specific on particular hypotheses or experimental conditions.

Timing

Data was collected continuously from June 10 to July 2, 2020

Data exclusions

A total of 4,937 responses were collected from which 915 individuals were screened out by quota questions (e.g., fell into household income, car ownership, and age bins that were already full) or failed to complete all sections of the survey. This left us with a final sample size of 4,022 responses, with 1,017 from Washington, D.C., 1,006 from Chicago, 1,001 from Seattle, and 998 from Dallas. Single-binary discrete choice (SBDC) experiments regarding compensation for giving up access to a private vehicle were asked only of respondents who reported having at least one household vehicle. Similarly, SBDC experiments regarding compensation for giving up access to ridehailing were asked only for participants who reported having used a ridehailing service before.

Non-participation

The authors do not know the number of invitations sent to potential respondents by Qualtrics, so cannot give a full picture of the response rate for the survey. Of 4,937 respondents who chose to voluntarily begin the survey, only 915 (or $18.5 \%$ ) were screened out or failed to complete the full questionnaire.

Randomization

For the Best-Worst Scaling (BWS) experiments, respondents were randomly allocated to one of two scenarios/framings: (1) typical year pre-COVID (e.g., 2019) and (2) recent month during COVID (e.g., May 2020).

\section{Reporting for specific materials, systems and methods}

We require information from authors about some types of materials, experimental systems and methods used in many studies. Here, indicate whether each material, system or method listed is relevant to your study. If you are not sure if a list item applies to your research, read the appropriate section before selecting a response.

Materials \& experimental systems

Methods

$\mathrm{n} / \mathrm{a}$ Involved in the study

$\mathrm{n} / \mathrm{a}$ Involved in the study

Х $\square$ Antibodies

Х $\square$ Eukaryotic cell lines

$\triangle \square$ ChIP-seq

Х $\square$ Palaeontology and archaeology

Х Flow cytometry

Х $\square$ Animals and other organisms

\ $\square$ MRI-based neuroimaging

$\bigotimes \square$ Human research participants

Х $\square$ Clinical data

$\bigotimes \square$ Dual use research of concern 